\title{
Modelo de Análise e Prevenção de Acidentes - MAPA: ferramenta para a vigilância em Saúde do trabalhador
}

\author{
Model of Analysis and Prevention of Accidents - MAPA: \\ tool for operational health surveillance
}

Ildeberto Muniz de Almeida ${ }^{1}$

Rodolfo Andrade de Gouveia Vilela ${ }^{2}$

Alessandro José Nunes da Silva ${ }^{3}$

Sandra Lorena Beltran ${ }^{2}$

${ }^{1}$ Departamento de Saúde Pública, Faculdade de Medicina de Botucatu, Universidade Estadual Paulista Júlio de Mesquita Filho. Av. Prof. Montenegro s/n, Rubião Junior. 18618970 Botucatu SP Brasil. ialmeida@fmb.unesp.br ${ }^{2}$ Faculdade de Saúde Pública, Universidade de São Paulo.

${ }^{3}$ Centro de Referência em Saúde do Trabalhador, Secretaria Municipal de Saúde de Piracicaba.
Abstract The analysis of work-related accidents is important for accident surveillance and prevention. Current methods of analysis seek to overcome reductionist views that see these occurrences as simple events explained by operator error. The objective of this paper is to analyze the Model of Analysis and Prevention of Accidents (MAPA) and its use in monitoring interventions, duly highlighting aspects experienced in the use of the tool. The descriptive analytical method was used, introducing the steps of the model. To illustrate contributions and or difficulties, cases where the tool was used in the context of service were selected. MAPA integrates theoretical approaches that have already been tried in studies of accidents by providing useful conceptual support from the data collection stage until conclusion and intervention stages. Besides revealing weaknesses of the traditional approach, it helps identify organizational determinants, such as management failings, system design and safety management involved in the accident. The main challenges lie in the grasp of concepts by users, in exploring organizational aspects upstream in the chain of decisions or at higher levels of the hierarchy, as well as the intervention to change the determinants of these events.

Key words Work-related accident, Method of analysis, Surveillance and prevention, Operational health
Resumo $A$ análise de acidentes de trabalho é importante para a vigilância e a prevenção desses eventos. Métodos atuais de análise buscam superar visões reducionistas que enxergam essas ocorrências como eventos simples explicados por erros dos operadores. O objetivo do artigo é analisar o modelo de análise e prevenção de acidentes (MAPA) e seu uso em intervenções de vigilância, destacando aspectos vivenciados na apropriação da ferramenta. Optou-se por método descritivo analítico apresentando as etapas do modelo. Para ilustrar contribuições e ou dificuldades foram selecionados casos nos quais foi usada a ferramenta em contexto de serviço. O MAPA integra abordagens teóricas já experimentadas em estudos de acidentes fornecendo apoio conceitual útil desde a etapa de coleta de dados à conclusão e intervenção. Além de revelar fragilidades da abordagem tradicional, ajuda a identificar determinantes organizacionais como falhas gerenciais, de concepção de sistemas e da gestão de segurança envolvidas na acidentalidade. Os principais desafios encontram-se no domínio dos conceitos pelos usuários, na exploração de aspectos organizacionais mais à montante na cadeia de decisões ou em níveis superiores da hierarquia, bem como na intervenção para mudanças nos determinantes destes eventos. Palavras-chave Acidente de trabalho, Método de análise, Vigilância e prevenção, Saúde do trabalhador 


\section{Introdução}

Acidentes de trabalho (AT) constituem o principal agravo à saúde dos trabalhadores no Brasil. Dados oficiais revelam verdadeira epidemia com elevados custos humanos, sociais e financeiros ${ }^{1}$. Tendo em vista seus impactos foram eleitos como prioridades de intervenção do Ministério do Trabalho e Emprego (MTE) e da Saúde (MS) por meio da Rede Nacional de Atenção integral à Saúde do Trabalhador (RENAST).

Trata-se de eventos complexos e multicausais, socialmente determinados, quase sempre previsíveis e preveníveis, com origens em rede de múltiplos fatores técnicos e sociais em interação². Alguns métodos de análise buscam superar visões reducionistas oriundas da segurança comportamental, que enxergam essas ocorrências como eventos simples explicados por erros dos operadores ou por aspectos técnicos pontuais normalmente contemplados nas normas legais.

Se bem analisados, os acidentes são oportunidades de aprendizado organizacional ${ }^{3}$ abrindo possibilidade de prevenção de novas ocorrências. Na prática cotidiana dos serviços, constata-se a necessidade de melhorar os métodos e a capacidade analítica dos profissionais da área, uma vez que a formação destes é influenciada pela abordagem tradicional, na qual ainda vigoram as abordagens oriundas das disciplinas clássicas como a medicina do trabalho, higiene e segurança do trabalho, que tendem a focalizar a atenção nos fatores de risco de acidentes, especialmente o comportamento dos operadores e ou aspectos técnicos próximos ao evento, deixando de lado os determinantes organizacionais, o que pode resultar em intervenções parciais e mesmo de baixa eficácia ${ }^{4}$.

Este texto apresenta e discute experiência de desenvolvimento e implantação do Modelo de Análise e Prevenção de Acidente de Trabalho $(\mathrm{MAPA})^{5}$, criado como instrumento para aprimorar o Sistema de Vigilância de Acidentes de Trabalho SIVAT Piracicaba ${ }^{6}$.

Optou-se por método qualitativo descritivo, de modo a abranger, a partir da percepção dos autores, a descrição de objetivos e principais etapas do modelo, seus pressupostos teóricos e ferramentas de apoio para a condução das análises, bem como sugestões de elaboração e implementação das propostas de prevenção.

Para ilustrar a utilização de conceitos, bem como o alcance e desafios na sua aplicação foram selecionados casos de análise e intervenção de modo a verificar se as ações ocorrem à luz das diretrizes da Vigilância em Saúde do Trabalhador (VISAT).

\section{Bases e origens conceituais do MAPA}

Nas últimas décadas foi crescente o número de estudos apoiados em conceitos de diferentes áreas do conhecimento dedicados a acidentes, com destaque para desastres, caracterizados por crítica ao reducionismo de análises tradicionais que explicam o ocorrido de modo centrado no indivíduo. Em contraposição, foram introduzidas ideias de acidente sistêmico ou (psico) organizacional estimulando compreensão desses eventos como fenômenos complexos com origens em redes de múltiplos fatores em interação e ou em inadequações da capacidade de adaptação desses sistemas às mudanças com que se deparam.

Sem preocupação com cronologia destacamse a seguir alguns dos campos de conhecimento e conceitos que participaram das origens do MAPA. Noções da Ergonomia da atividade trouxeram aportes para a compreensão da atividade real ou de comportamentos humanos em situações de trabalho ${ }^{7,8}$.

Perrow desenvolveu teoria de acidente normal ou sistêmico e destacou contribuições da complexidade interativa, uma propriedade desses sistemas nas origens de acidentes ${ }^{9}$. Em 1997, Turner e Pidgeon reeditaram obra de $1978 \mathrm{em}$ que, pela primeira vez, foi usada a noção de desastre feito pelo homem para descrever ocorrências em sistemas que incorporavam modernas tecnologias ${ }^{10}$. Reason e Llory retomaram a noção de modelo de acidente organizacional de Turner e Pidgeon, difundindo ideias como falhas ativas, condições latentes, incubação do acidente, acidentes sem falhas ativas ou erros humanos ${ }^{3,11}$. Em sintonia com as abordagens sistêmicas Rasmussen introduziu as bases do modelo SRK ("skill -rule-knowledge") relativo a níveis ou formas de gestão psíquica em consonância com os tipos de situações, ou seja, rotineiras, baseada em regras e ou em conhecimentos ${ }^{12}$. Os trabalhos de Reason contribuíram para o uso dessa noção em análises de acidentes pelo mundo todo. No Reino Unido, o Health and Safety Executive (HSE) recomendou formalmente a exploração da forma de gestão psíquica na tarefa em análises de acidentes ${ }^{13}$. Amalberti avançou nesse campo destacando a importância das noções de compreensão e de quebra de compromisso cognitivo na segurança e confiabilidade de sistemas ${ }^{14}$. Vaughan realizou estudo de antropologia histórica na NASA explicando o desastre da nave espacial Challenger 
com a noção de normalização de desvios ${ }^{15}$ que parece ter influenciado a noção de migração de sistemas para acidentes trabalhada por Rasmus$\operatorname{sen}^{16}$ e Dekker ${ }^{17}$. Segundo esses autores, as mesmas estratégias usadas nos sistemas para lidar com sucesso, com constrangimentos advindos da escassez de recursos e pressões de produtividade, contribuiriam para os acidentes.

Enfoque especial vem sendo dado à noção de armadilhas cognitivas não apenas em casos que envolvam omissões em passos de tarefas como em situações já descritas como de surpresas automáticas, erros de modo, by-passes previsíveis, feedbacks que obstaculizam ou impedem a compreensão dos operadores sobre modo ou estado do sistema, etc. ${ }^{17,18}$. Llory e Montmayeul enriquecem a discussão afirmando que os aspectos técnicos e organizacionais estão profundamente relacionados e se complementam, o que cria um problema, pois enquanto os aspectos técnicos dizem respeito às ciências da engenharia, os organizacionais dizem respeito a conhecimentos sobre o homem e a organização, às ciências humanas e sociais ${ }^{19}$. Enquanto os aspectos técnicos propiciam aproximação explicativa fundamentada em noções de causalidade e objetividade - uma explicação racional do acidente pelo encadeamento de causas e efeitos (técnicos e humanos) -, analisados tipicamente com métodos como árvores de falhas, árvores de causas etc, aspectos organizacionais requisitam aproximação compreensiva fundamentada na noção de intersubjetividade e de causalidades diferentes. Os autores então propõem método denominado de análise organizacional, uma análise densa da organização explorando as dimensões transversal, vertical e a dimensão temporal histórica.

Quais os impactos da emergência dessas contribuições e, em particular, de seu uso em estudos de acidentes? A resposta a essa questão ainda está por ser construída, mas fato é que muitas delas parecem ter influenciado: a) emergência de novas técnicas de análises como os chamados mapas verticais de acidentes ${ }^{20}$ e a nova proposta do Health and Safety Executive ${ }^{13}$; b) conteúdos de treinamentos de equipes de análises de acidentes $^{21}$; c) novas práticas de vigilância de acidentes como o projeto Workgroup Occupational Risk Model (WORM), na Holanda, que deu destaque ao modelo da gravata-borboleta como representação do fenômeno acidente ${ }^{22}$.

A difusão dessas contribuições no Brasil tem sido restrita e acontece principalmente em iniciativas de universidades e instituições de pesquisa. A maioria dessas obras não foi lançada no país.
Apenas o método de árvore de causas, desenvolvido no início dos anos 70 e parcialmente inspirado nessa trajetória conceitual, ganhou relativa difusão entre nós ${ }^{23}$. Posteriormente, lidando prioritariamente com acidentes ampliados, Freitas et al. desenvolveram proposta de análise interdisciplinar e participativa de acidentes (AIPA) inspirada na análise sociotécnica de acidentes industriais ${ }^{24}$, Paté-Cornell, na França. A elaboração do MAPA também se deu em diálogo com conceito de vigilância em saúde tido como eixo orientador de práticas da Vigilância em Saúde do Trabalhador (VISAT), que se caracteriza por abranger três níveis de atuação: sobre as causas ou determinantes; sobre os riscos ou exposição e sobre os danos ou consequências ${ }^{25-27}$.

Esse conceito possibilita situar a dimensão das causas ou macrodeterminantes em escolhas políticas estratégicas relativas ao desenvolvimento econômico e tecnológico, à regulação e legitimação de riscos. A noção de VISAT ampliou explicitamente os horizontes da intervenção para além dos limites do sistema empresa, de modo a alcançar determinantes de condições latentes e origens incubadas de acidentes.

Atuar em consonância com esse enfoque exige ampliações dos objetos de ação, de recursos mobilizados e do espaço de atuação para além dos limites do setor saúde ${ }^{25-27}$.

A experiência de desenvolvimento do MAPA pressupõe que conceitos sugeridos em campos de conhecimento diversos podem ser assumidos como guias de construção de diferentes narrativas de redes de fatores envolvidos em origens de acidentes ${ }^{3,7,11,18,19}$.

\section{A análise de acidentes segundo o MAPA}

O MAPA teve seu desenvolvimento inspirado na ideia de que grande parte dos conceitos que vêm sendo usados nas últimas décadas em análises de desastres e acidentes ampliados pode ser usada em análises de acidentes de trabalho do tipo que habitualmente é enfrentada na VISAT. Não se tratava de reinventar a roda, mas facilitar aos integrantes dessas equipes a apropriação de concepção e ferramentas já testadas com sucesso em outras situações de análises de acidentes e em diálogo com a forma como se dava no SUS a implantação de ações de vigilância de acidentes do trabalho.

A escolha adotada no MAPA foi a de associar, em uma mesma análise, narrativas guiadas por conceitos da ergonomia da atividade, da análise de barreiras, da análise de mudanças e até em 
outros conceitos de acordo com o caso. Partindo da ideia de que cada caso é único e acontece em momento histórico singular, as análises baseadas no MAPA se aproximam da abordagem da análise organizacional proposta por Llory e Montmayeul $^{19}$, que estimula estudo clínico em profundidade, cujas etapas devem propiciar a montagem de quebra cabeça que possibilite compreensão de aspectos técnicos e organizacionais envolvidos na ocorrência. No modelo, a escolha da gravata-borboleta ${ }^{22}$ como representação desses eventos ressalta a necessidade de incluir, mas ultrapassar os aspectos proximais habitualmente contemplados nas análises feitas no âmbito das empresas. A gravata-borboleta (Figura 1) destaca a existência de origens e consequências proximais e distais nesses eventos.

$\mathrm{O}$ acidente passa a ser compreendido como ocorrência com história a ser narrada e, ao mesmo tempo, a equipe de vigilância passa a ser estimulada a não declarar encerrada sua atividade enquanto não identificar condições do sistema associadas às suas origens (e eventualmente consequências), mesmo as mais remotas.

Os conceitos selecionados como guias de construção de diferentes narrativas do acidente foram os de: a) descrição sistemática do trabalho normal ou real em conformidade com a Ergonomia da Atividade seguida de descrição do acidente apoiada nas noções apontadas a seguir; b) análise de barreiras, a ser concluída em termos de falhas na gestão de segurança e saúde no trabalho, associada ou não a falhas de concepção e em outros subsistemas de gestão; c) análise de mudanças concluída em termos de falhas na organização do trabalho e falhas em subsistemas de gestão de pessoal, de material, de manutenção, de materiais, de projetos, de comunicações etc, de acordo com a situação específica; e d) ampliação conceitual, a ser usado quando se considere

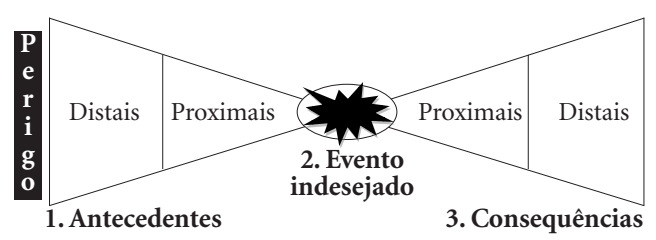

Figura 1. Modelo da Gravata borboleta.

Adaptado de Hale et al. ${ }^{22}$. que algum dos conceitos já usados em estudos de acidentes pode ser útil, aportando novas contribuições e narrativa adicional ao caso. Os exemplos mais facilmente reconhecidos por equipes de análises parecem ser os de uso das noções de armadilha cognitiva e ou by-passes previsíveis em acidentes em que o trabalhador omitiu passos ou adotou atalhos e estava sendo culpabilizado.

Idealmente, as intervenções devem estimular aperfeiçoamentos das políticas públicas que abordem o universo das consequências de saúde, sociais, ambientais, jurídicas etc., de acidentes propondo mudanças em características sóciotécnicas dos sistemas em questão, por exemplo, recomendando melhorias na concepção de subsistemas técnicos, interditando práticas sociais que fragilizam a segurança e a saúde de trabalhadores no conjunto de empresas que realizam a mesma atividade ou que compõem a cadeia de produção em questão.

Intervenções baseadas no MAPA também buscam estimular diálogos entre as diferentes lógicas ou interesses presentes e em disputa no sistema em que se deu o acidente, de modo a propiciar a construção de novos tipos de processos de decisões que considerem os interesses de todos ou do maior número possível de atores envolvidos e não apenas aqueles de curto prazo do tomador de decisão. Caso as narrativas obtidas incluam exemplos evidentes de como escolhas adotadas em um segmento, geralmente de mais poder, do sistema interferiram negativamente em outros subsistemas, é possível estimular mudanças de natureza democratizadora das relações no interior desse sistema. A narrativa apoiada em conceitos da Ergonomia da atividade ${ }^{7,8}$ tende a evidenciar que as práticas tradicionais de gestão sistematicamente excluem de suas negociações o ponto de vista dos trabalhadores, ou seja, daqueles que se expõem aos riscos e recebem a fatura do custo humano do trabalho. Essa é, portanto, uma das lógicas que o processo de negociação aberto em defesa da prevenção deve procurar empoderar.

A proposta do MAPA embute questões que permitem checar os desfechos estabelecidos em cada caso. Entre elas, destacam-se: $\mathrm{O}$ acidente é explicado como fenômeno sociotécnico com origens organizacionais e gerenciais? Problemas localizados, descumprimento flagrante de normas são alvo de recomendações específicas? Há recomendações de prevenção e de proteção em conformidade com modelo da gravata-borboleta? A explicação final contempla as três dimensões da VISAT e propõe recomendações em todas elas? O diagnóstico, as recomendações firmadas e as ne- 
gociações estabelecidas estimulam protagonismo dos trabalhadores?

\section{Contribuições e dificuldades percebidas em análises de acidente conduzidas com apoio do MAPA}

Numa prensa em que atuavam três trabalhadores e em que a descida do martelo era comandada por apenas um deles uma ajudante sofreu amputação depois que seu colega acionou esse comando $^{28}$. A máquina era de grande porte e praticamente ocultava a vítima que trabalhava do lado oposto ao do colega responsável pelo comando bimanual.

A análise mostrou ser a primeira vez que a vítima trabalhava naquela máquina e a compreensão do ocorrido foi facilitada ao se buscar esclarecer como era o trabalho normal (habitual sem acidente) naquela prensa. Quem eram os operadores habituais? Como o responsável pelo acionamento sabia que já podia comandar a descida do martelo? Em que consistia o trabalho da novata e que variabilidades de sua atividade poderiam prolongar sua permanência na zona de prensagem? Como eram tomadas as decisões que culminaram com a indicação da ajudante para o trabalho naquele equipamento?

O conceito de trabalho real oriundo da ergonomia da atividade ${ }^{7,8}$ recomendado no MAPA se revela ferramenta de apoio à análise incentivando que a equipe de vigilância formule perguntas desse tipo.

Esse mesmo caminho levou a equipe que analisou acidente com picada de agulha em um hospital a esclarecer tratar-se de evento em que a vítima cuidava de paciente "de uma de suas colegas” (e não dela), ocorrido em horário matinal de troca de turnos, que encavalava com o de transporte de pacientes agendados para procedimentos eletivos para centro cirúrgico, e com período de admissão de pacientes de convênios, não SUS, com cirurgias eletivas marcadas para aquele mesmo dia. Essa forma de organizar as três atividades criava outros tipos de dificuldades sentidas no serviço, seja quando de demora de pessoas agendadas, seja de atrasos no transporte de pacientes para o centro cirúrgico seja de concomitância com recebimento de informações relativas aos grupos a serem cuidados pela equipe que entrava.

As narrativas abrangem o trabalho normal, variabilidades de componentes como o responsável pela execução da tarefa nos casos acima, interações com supervisores hierárquicos e ou- tros colegas enfatizando estratégias, modos operatórios usados, constrangimentos mais comuns, margens de manobras e adaptações ou ajustes adotados pelos operadores de modo a considerar perigos, riscos e medidas de prevenção nas diferentes situações. No exemplo do setor saúde, nota-se que a equipe tinha margem de manobras para lançar mão da cooperação e que tal recurso era habitual, já tendo sido usado com sucesso em outras situações. Os desafios desse tipo de análise passam a ser não só descrever quais e como são essas estratégias na "vida como ela é", como esclarecer as razões de seu fracasso por ocasião do acidente. Essa compreensão é facilitada para quem conhece o que esteve associado ao seu uso com sucesso no passado.

Esse caminho de descrição já representa um primeiro movimento no sentido da ampliação conceitual da análise apoiado na Ergonomia. Diferentemente das abordagens tradicionais que tendem a descrever o acidente se referindo a descumprimento de normas, esse tipo de narrativa os situa como eventos em estreita relação com decisões habitualmente tomadas pelas chefias de serviços ou grupos de trabalhadores ao lidar com constrangimentos e manter os sistemas em funcionamento. Se o trabalho realizado por ocasião do AT foi descrito nessa fase, a condução e compreensão do restante da análise tende a ser facilitado ${ }^{29}$.

\section{Narrativas do acidente propriamente dito}

O modelo recomenda três ajudas para descrição do acidente propriamente dito. A primeira é a descrição sucinta do ocorrido: as conseqüências, com ênfase nas lesões sofridas pela vítima; $\mathrm{o}$ acidente propriamente dito que provocou essas lesões e as origens imediatas desse evento.

$\mathrm{Na}$ experiência de vigilância de acidentes em Piracicaba, o uso do MAPA foi fundamental na introdução de exploração de consequências tardias de acidentes. No caso da picada de agulha, a existência de norma relativa à conduta terapêutica e ao acompanhamento do estado sorológico da vítima por até seis meses no pós-acidente ilustra de modo mais claro que o evento não deve ser considerado encerrado na lesão provocada pela agulha. Nesse acidente e em todos envolvendo traumas, a busca de sequelas ou lesões tardias, inclusive na esfera mental, vem se tornando usual.

As outras duas ajudas sugeridas no modelo como guias da construção de narrativas adicionais do caso são os conceitos de análises de mudanças e análises de barreiras. 


\section{Análise de Mudanças}

O roteiro inclui sugestões de questões que visam esclarecer razões associadas a mudanças ocorridas no acidente. O processo é mais simples e direto quando se trata de esclarecer aspectos das origens de dimensão técnica envolvida no acidente como a quebra de um equipamento, um incidente, choque elétrico, explosão, intoxicação, etc. A mudança deve ser identificada de modo específico e as perguntas sobre suas origens exploradas buscando "causas das causas". Com esse procedimento, consegue-se chegar a contribuições de aspectos sociais ou comportamentais, que também devem ser explorados de modo a esclarecer padrões de decisões adotados no sistema quando em face de variabilidades.

Como são designados substitutos quando o operador titular falta ao trabalho? Quem e como decide que a colhedora de cana vai ser usada para desencalhe do trator de transbordo ao invés de aguardar a chegada de trator "certo" para essa tarefa? Como se explica que o equipamento novo tenha sido recebido e instalado com defeito na fiação e que não tenha sido aterrado conforme normas da empresa? Como se dá na empresa a programação simultânea de duas atividades em que uma requer o sistema ligado e a outra, desligado? Como se explica que o dispositivo recebido pela equipe para ser instalado seja de formato e dimensões diferentes daquele a ser retirado e não encaixe no equipamento a ser consertado?

No acidente da prensa a análise mostrou que o comando bimanual estava com defeito e foi mantido em operação, desconsiderando implicações dessa condição na segurança da máquina. O defeito fazia com que alguns comandos de descida do martelo não fossem obedecidos, ou seja, falhassem, exigindo novo acionamento. Essa condição introduzia fator potencial de confusão para o operador, porque a não descida do martelo também acontecia se o comando de descida fosse acionado durante o período em que algum dos trabalhadores tivesse inserido partes do corpo na zona perigosa da máquina, provocando a frenagem por conta dos sensores da cortina de luz.

Essa narrativa pode evoluir de modo que permita alcançar a dimensão transversal da empresa e identificar problemas e falhas gerenciais diversas, de acordo com a situação: falhas na gestão de mão-de-obra, de manutenção, de suprimentos, de gestão de segurança, na divisão de tarefas, de comunicações, etc.

$\mathrm{Na}$ análise de mudanças, o acidente é explicado com origens naquilo que estava presente no sistema e não como resultado da falta ou ausência de algo. Se a narrativa tende a explicar o ocorrido como evento sem mudanças a equipe deve ser cuidadosa na análise de barreiras. $\mathrm{O}$ trabalho real pode estar se dando em condições que lembram "acidente esperando para acontecer".

\section{Análise de barreiras}

A análise de barreiras explica o acidente pela falta ou falha de barreiras de prevenção e de proteção contra fontes de energia potencial ou nocividades identificadas na empresa. Os problemas identificados devem ser adotados como pontos de partida de exploração das suas origens. Que aspectos do sistema permitiram suas origens?

As perguntas devem explorar aspectos do ciclo de vida das barreiras: concepção; instalação, operação, manutenção, qualidade e vida útil de seus componentes.

No exemplo já citado da prensa, o perigo de prensagem de partes do corpo de trabalhador na zona de operação da máquina, é evidente. A análise mostrou descumprimento de norma que exigia tantos comandos bimanuais quantos fossem os trabalhadores na máquina e também que o sistema de frenagem associado aos sensores de presença não impediu a descida do martelo quando a trabalhadora estava dentro da zona perigosa da máquina.

A conclusão da análise de barreiras tende a se dar na forma de falhas na gestão de segurança e saúde do trabalho e meio ambiente (SGSSTA). No caso dessa prensa emerge também a possibilidade de falhas na contratação de serviço especializado. Afinal, ou a contratante não soube avaliar ou preferiu aceitar erros grotescos na montagem dos dispositivos de prevenção na prensa, como foi o caso da possibilidade de seu acionamento por apenas um dos trabalhadores.

\section{Ampliação conceitual da análise}

De acordo com o MAPA é fundamental que a análise busque explicar, e não julgar, os comportamentos de trabalhadores que contribuíram para o ocorrido. Aplicadas ao exemplo da prensa, as palavras de Dekker seriam "cabe à equipe de análise buscar compreender por que, para o operador, fazia sentido acionar o comando com a colega ainda embaixo do martelo" ${ }^{17}$. E não mais atribuir a causa do corrido a esse comportamento.

Vale lembrar que a máquina era apresentada pela empresa como protegida, em conformidade com exigências legais e apresentava cortina de luz 
visível, instalada verticalmente, na área de entrada de suas zonas perigosas estimulando ilusão de segurança. A situação era agravada por condição desconhecida pelos trabalhadores, a saber, que a frenagem do martelo comandada por sinais enviados pelos sensores de detecção de presença era temporizada. Passado o tempo programado, uma vez acionado, o martelo desceria.

\section{O MAPA como ferramenta da vigilância de acidentes em ST}

\section{Queda em altura de montagem}

de plataforma em usina de açúcar

$\mathrm{O}$ acidente fatal ocorreu com o Sr K, trabalhador de empresa de montagem industrial contratada por terceira, que prestava serviço de instalação de novas caldeiras de bagaço de cana antecedendo início de safra em usina de açúcar. A atividade era de montagem de esteiras de alimentação de caldeiras fundamentais para a retomada do processo de moagem e estava atrasada tanto por falta de materiais quanto em função de chuvas. No período que antecedeu ao acidente, a vítima trabalhou, em média, 10,44h/dia, durante 25 dias seguidos, sem nenhuma folga. Nesse período trabalhou 261 horas, sendo 54\% normais e $46 \%$, extras ${ }^{5}$.

No dia do AT, um sábado, trabalhara 12 horas e ainda trabalharia por mais duas. Por volta das 19h50min teve inicio uma chuva e a chefia determinou o recolhimento do material em plataforma mal iluminada, a $21 \mathrm{~m}$ de altura, quando caiu por buraco presente no piso metálico, que estava em fase de finalização. A análise de barreiras revelou falhas na gestão de segurança do trabalho, em especial contribuições de falta de barreiras de prevenção definidas em lei. Não havia sistema de permissão de trabalho para intervenções em altura e nem especificação e ou checagem de requisitos de segurança a serem observados pelas contratadas que, por sua vez, não possuíam serviços de gestão de segurança. A usina não possuía qualquer controle sobre a atividade das contratadas. A observação no local de acidente constatou que nenhum dos trabalhadores, inclusive chefias aderia ao uso de cinto de segurança para proteção contra quedas de altura.

A conclusão revelou o acidente emergindo de práticas de gestão apoiadas em contratação de serviços de terceiras e subcontratadas em conjunto com falhas de logística, em especial falta de materiais necessários, ensejando atrasos que, por sua vez, alimentavam aumento de pressões de produção, repassado à cadeia de contratadas, desrespeitando abertamente normas trabalhistas e estimulando degradação progressiva de condições e capacidade de trabalho.

A intervenção preventiva nesse caso se deu em colaboração com o Ministério Público do Trabalho, com negociação de Termo de Ajuste de Conduta cujas cláusulas obrigavam a usina a adotar sistema de gerenciamento de serviços de terceiros e estratégias de controle e diminuição dos ritmos de trabalho. Ou seja, diferentemente de abordagens tradicionais que, em casos assemelhados, poderiam tender a centrar-se em exigências de respeito às normas de prevenção de quedas em altura, optou-se por, sem ignorar esse aspecto, abordar a contratação de serviços de terceiros em toda a sua amplitude.

Um dos limites da intervenção está no fato de seu alcance restringir-se a apenas uma empresa e não ao conjunto das que atuam na mesma atividade no município, região, estado ou país. Olhar para esse tipo de exemplo, com foco na dimensão de macrodeterminação, permitiria questionar a forma como se dá atualmente a regulação de práticas de terceirização, estimulando a politização do debate sobre os caminhos da prevenção.

Numa fábrica de móveis populares, cuja produção era destinada exclusivamente a uma grande rede de lojas, o CEREST Piracicaba detectou verdadeira epidemia de acidentes envolvendo o uso de grampeadores industriais ${ }^{30}$.

A análise dos casos mostrou que os grampeadores, eram dotados de barreiras de prevenção, que eram retiradas logo que eram recebidos na fábrica. $\mathrm{O}$ olhar tradicional estimulava ideia de que a mera determinação de uso dessas proteções resolveria a questão, mas a equipe resolveu investigar as razões que explicavam aquela retirada e as resistências da empresa a essa "solução" simples, que apesar de exigida repetidas vezes não era acatada.

A retirada das proteções e o insucesso das intervenções anteriores viraram pontos de partida da análise. O trabalho de montagem exigia de cada operador cerca de 50.000 disparos do grampeador por dia, com modos operatórios que aproximavam grampos de partes do corpo do trabalhador e de colegas. O uso do grampeador com proteções exigia mais esforço e imobilização das estruturas a serem grampeadas para impedir o acionamento do grampo ao ar livre, o que tornava as operações mais lentas e dificultava o alcance das metas de produção.

Acidente analisado com o MAPA evidenciou ainda que o atraso na produção no dia anterior impedira o fechamento de carga de um cami- 
nhão com prazo de entrega e que o sistema não possuía margem de manobras que permitissem equacionar o atraso com reprogramação de prazos de entrega, mobilização de outros recursos ou ajuda de outras equipes. A estratégia adotada, na tentativa de retirar o atraso, era a intensificação do ritmo de produção numa situação em que o sistema já dava sinais de degradação, em especial, rotatividade de $85 \%$ da força-de-trabalho e perdas elevadas da produção que implicavam em retrabalho.

A análise do funcionamento da empresa associou o uso do MAPA com a abordagem da ergonomia da atividade ${ }^{8}$ e possibilitou detectar que a retirada das proteções era aceita pelos trabalhadores, pois as equipes de montagem recebiam um salário base (piso da categoria) adicionado a um bônus mensal a título de Participação nos Lucros e Resultados (PLR), que, a depender da quantidade mensal de sofás produzida pelas equipes, mais que dobrava o salário inicial. No entanto, legalmente o PLR só poderia ser parcelado em duas vezes ao final do ano. O pagamento mensal era de interesse dos trabalhadores e havia sido acordado com o Sindicato de Trabalhadores. Como intervir em tais condições? Ao apontar a relação entre acidentes e pagamento por produção, o CEREST Piracicaba ficou isolado dada a defesa dessa prática pela empresa e pelo sindicato de trabalhadores. No entanto, a alta taxa de acidentes era apenas um dos aspectos da patologia organizacional. O pagamento por produção induzia a uma degradação da qualidade dos sofás. Cerca de 30\% deles voltavam para retrabalho na fábrica.

A negociação conduzida envolveu também a busca de solução pontual que resultou na substituição do grampeador por outro descrito como adequado pelos trabalhadores, por não lhes exigir aumento de esforço na operação. Alguns anos depois a empresa sofreu importante revés ao perder seu principal cliente e reduziu substancialmente seu efetivo. A equipe do CEREST Piracicaba não conseguiu fazer com que a negociação envolvesse a cadeia produtiva de fabricantes e fornecedores de móveis à rede nacional contratante da produção. Em princípio, a situação permitia pensar que problemas assemelhados se repetissem em outros fornecedores, indicando a necessidade de inclusão na agenda política de ST de discussões sobre a constituição de instâncias Intersetoriais, estaduais e nacional, capazes de agir como condutor, dinamizador e ou coordenador desse tipo de intervenção de vigilância.

\section{Considerações finais: desafios da intervenção}

É possível afirmar que as experiências atuais de uso do modelo por parte de equipes de vigilância em saúde do Trabalhador assumem dois formatos distintos: intervenções centradas em análises de acidentes, vivenciadas como processos isolados de vigilância, e intervenções que associam análise e esboço de diagnóstico organizacional do sistema em questão. No primeiro grupo, as intervenções da equipe em empresas são centradas no acidente e seu alcance parece mais limitado no tempo e no espaço. As análises e intervenções que ampliam seu objeto para os determinantes organizacionais colocam mais desafios, exigem mais tempo e maturação dos atores.

A experiência permite inferir que os conceitos usados se mostram úteis como guias de construção de diferentes narrativas do acidente. O MAPA não criou essas formas de conduzir narrativas, mas as aglutina e incentiva difusão atualizada de cada uma delas. Além disso, as equipes têm recebido treinamentos e têm a possibilidade de interlocução apoiada em página internet do fórum de acidentes de trabalho http://forumat. net.br/at/ e ou e-mails. No entanto, as atividades de capacitação se limitam às equipes de vigilância e pouco dialogam com os trabalhadores e outros profissionais no interior das empresas.

A possibilidade de associar achados das diferentes narrativas amplia leque de argumentos passíveis de uso quando de negociações ou enfrentamentos com representantes de empresa, como subsídios à elaboração de propostas de negociações a serem construídas como desfechos dessas intervenções e diminui chances de lacunas nas análises.

As reflexões aqui apresentadas surgiram de processo de discussão que incluiu numerosas idas e vindas no uso do MAPA. As dificuldades identificadas parecem indicar não só a necessidade de formação precedendo a adoção do modelo, como a de oferta de apoio e interlocução permanente com as equipes, a exemplo do que se pretende com as experiências virtuais e presenciais do fórum de acidentes de trabalho.

Os fatos apresentados levam a considerar a experiência até aqui como animadora. As dificuldades identificadas, no que se refere à apropriação conceitual, podem ser consideradas esperadas num contexto de serviço. O mesmo se pode dizer em relação às propostas de intervenções que visam desencadear processos de negociação pela prevenção, trazendo para a ordem do dia 
questões relacionadas às escolhas estratégicas das empresas no que se refere às formas como decidem organizar a produção.

O MAPA, enquanto ferramenta de análise, centrada no papel do agente de inspeção ou do pesquisador externo à organização, precisa ser articulado a uma metodologia participativa e de aprendizado nos locais de trabalho, de modo que o conhecimento e a inovação do olhar não se restrinjam à equipe de vigilância que conduz a análise. Por outro lado, a intervenção e a criação de soluções requisita ampliação e comprometimento dos atores implicados na situação. Sem estes pré-requisitos, o diagnóstico será sempre externo e parcial, pois seus achados não passaram pelo crivo da resistência do real. Segundo Virkkunen et al. ${ }^{31}$, para conhecer é preciso também transformar. Esta transformação, para ser sustentável e duradoura, terá que passar pela confrontação e mudança dos diferentes pontos de vista existentes no interior das organizações, de modo a associar o diagnóstico à criação conjunta de soluções, como preconizado, por exemplo, em ferramentas de intervenção formativa como o Laboratório de Mudanças ${ }^{32}$.

O MAPA associa a utilização de conceitos sociotécnicos com estratégias que reconhecem nos trabalhadores o papel de protagonistas na defesa de sua saúde no trabalho. No formato atual, condizente com a atual conjuntura de pouca participação da sociedade civil, a dinamização do uso da proposta ainda se mostra dependente da contribuição de profissionais dos serviços envolvidos. A despeito de obter diagnósticos organizacionais, as recomendações oriundas das análises efetuadas com o MAPA encontram dificuldades de serem acolhidas pelas organizações, mesmo quando pressionadas pelos órgãos públicos em atuação intersetorial. Uma das razões é que as mudanças organizacionais requeridas escapam à lógica produtiva vigente, ou seja, sua implementação requer, além de diagnósticos, um reposicionamento das organizações diante do problema, que pressupõe desde o seu reconhecimento en- quanto tal, até mudanças culturais e de posturas, tais como a valorização do saber prático. Enfim, pressupõe uma interação diferenciada entre os atores no interior das próprias organizações e destes com os agentes públicos ${ }^{33}$. Esforços nesta direção parecem necessários e deverão ser pensados em próximas iniciativas, de modo a ampliar o leque de alianças, o alcance e os impactos das ações públicas em defesa da vida.

\section{Colaboradores}

IM Almeida e RAG Vilela participaram da elaboração do manuscrito em todas as fases. AJ Nunes da Silva e SL Beltran contribuíram na revisão bibliográfica e na apresentação e discussão dos casos.

\section{Agradecimentos}

À FAPESP pelo apoio aos três projetos de pesquisa que fundamentaram este texto e à Equipe do CEREST Piracicaba e aos Procuradores do Ministério Público do Trabalho da 15a Região pelas parcerias e viabilização das pesquisas. 


\section{Referências}

1. Santana V, Nobre L, Waldvogel BC. Acidentes de trabalho no Brasil entre 1994 e 2004: uma revisão. Cien Saude Colet 2005; 10(4):841-855.

2. Dwyer T, Raftery A. Industrial accidents are produced by social relations of work: A sociological theory of industrial accidents. Appl. Ergon. 1991; 22(3):167-178.

3. Llory M. Acidentes Industrias: o custo do silencio. Rio de Janeiro: Multimais; 1999.

4. Vilela RAG, Almeida IM, Mendes RWB. Da vigilância para prevenção de acidentes de trabalho: contribuição da ergonomia da atividade. Cien Saude Colet 2012; 17(10):2817-2830.

5. Almeida IM, Vilela RA. Modelo de Análise e Prevenção de Acidentes de Trabalho-MAPA. Piracicaba: CEREST Piracicaba; 2010. p. 52.

6. Cordeiro R, Vilela RAG, Medeiros MAT, Gonçalves CGO, Bragantini CA, Varolla AJ, Stephan C. O sistema de vigilância de acidentes do trabalho de Piracicaba, São Paulo, Brasil. Cad Saude Publica 2005; 21(5):15741583.

7. Assunção A, Lima F. A contribuição da ergonomia para a identificação, redução e eliminação da nocividade do trabalho. In: Mendes R, organizador. A Patologia do Trabalho. São Paulo: Atheneu; 2001. p. 1768-1789.

8. Guérin F. Compreender o trabalho para transformá-lo: a prática da ergonomia. São Paulo: Edgard Blücher; 2001.

9. Perrow C. Normal Accidents: Living with High Risk Technologies. Princeton: Princeton University Press; 1999.

10. Turner BA, Pidgeon NF. Man-made Disasters. $2^{\text {nd }}$ ed. London: Butterworth-Heinemann; 1997.

11. Reason JT. Managing the risks of organizational accidents. Michigan: Ashgate; 1997.

12. Rasmussen J. Skills, Rules, and Knowledge - Signals, Signs, and Symbols, and other distinctions in human -perfomance models. IEEE Trans. Syst. Man Cybern 1983; 13(3):257-266.

13. Health and Safety Executive. Investigating accidents and incidents. London: Her Majesty's Stationery Office; 2004.

14. Amalberti R. La Conduite de Systèmes à Risques. Paris: Press Universitaires de France; 1996.

15. Vaughan D. The trickle-down effect: Policy decisions, risky work, and the Challenger tragedy. California $\mathrm{Ma}$ nage. Rev. 1997; 39(2):80-102.

16. Rasmussen J. Risk management in a dynamic society: A modelling problem. Safety Sci 1997; 27(2-3):183-213.

17. Dekker PS. Drift into Failure: From Hunting Broken Components to Understanding Complex Systems. Farnham: Ashgate Publishing Limited; 2012.

18. Woods DD, Dekker PS, Cook RI, Johannesen L, Sarter N. Behind Human Error. $2^{\text {nd }}$ ed. Farnham: Ashgate Publishing Limited; 2012.

19. Llory M, Montmayeul R. L'accident et l'organisation. Bordeaux: Préventique; 2010.

20. Rasmussen J, Svedung I. Proactive risk management in dynamic society. Karlstad: Swedish Rescue Services Agency; 2000.

21. Reason JT, Hobbs A. Managing Maintenance Error: A Practical Guide. Farnham: Ashgate; 2003.
22. Hale AR, Ale BJM, Goossens LHJ, Heijer T, Bellamy LJ, Mud ML, Roelen A, Baksteen H, Post J, Papazoglou IA, Bloemhoff A, Oh JIH. Modeling accidents for prioritizing prevention. Reliab. Eng. Syst. Safe 2007; 92(12):1701-1715.

23. Binder MCP. O uso do método de árvore de causas na investigação de acidentes de trabalho típicos. Rev. Bras. Saúde Ocup 1997; 23(87/88):69-92.

24. Freitas CM, Porto MFS, Machado JMH. Perspectivas para uma Análise Interdisciplinar e Participativa (AIPA) no contexto da indústria de processo. In: Freitas C, Porto M, Machado J, colaboradores. Acidentes industriais ampliados: desafios e perspectivas para o controle e a prevenção. Rio de Janeiro: Fiocruz; 2000. p. 49-81.

25. Machado JMH. A propósito da Vigilância em Saúde do Trabalhador Cien Saude Colet 2005; 10(4):987-992.

26. Paim J. A reforma sanitária e os modelos assistenciais. In: Rouquayrol M, Almeida-Filho N, organizadores. Epidemiologia e Serviços de Saúde. Rio de Janeiro: Medsi; 1999. p. 473-487.

27. Porto MFS. Uma ecologia política dos riscos: princípios para integrarmos o local e o global na promoção da saúde e da justiça ambiental. Rio de Janeiro: Editora Fiocruz; 2007.p. 244

28. Almeida IM, Nobre Júnior H, Amaral Dias MD, Vilela RAG. Safety illusion and error trap in a collectively-operated machine accident. Work 2012; 41(Supl. 1):3202-3206

29. Diniz EPH, Assunção AA, Lima FPA. Prevenção de acidente s: o reconhecimento das estratégias operatórias dos motociclistas profissionais como base para a negociação de acordo coletivo. Cien Saude Colet 2005; 10(4):905-916.

30. Almeida IM, Vilela RAG, Gomes MHP, Prado H, Nunes da Silva AJ. Pressão por produção e Acidentes: estudo a partir de acidente com ferramenta manual em fábrica de móveis. In: Lourenço E, Navarro V, Bertani I, Silva JS, Sant'ana R, organizadores. $O$ avesso do trabalho: Trabalho, precarização e saúde do trabalhador. $2^{\mathrm{a}}$ ed. São Paulo: Editora Expressão Popular; 2010. p. 229-252.

31. Virkkunen J, Vilela RAG, Querol MAP, Lopes MGR. O Laboratório de Mudança como ferramenta para transformação colaborativa de atividades de trabalho: uma entrevista com Jaakko Virkkunen. Saúde Soc 2014; 23(1):336-344.

32. Pereira-Querol M, Jackson Filho J, Cassandre M. Change Laboratory: uma proposta metodológica para pesquisa e desenvolvimento da Aprendizagem Organizacional. Administração: Ensino e Pesquisa 2011; 12(4):609-640.

33. O'Dwyer G, Reis DCS, Silva LLG. Integralidade, uma diretriz do SUS para a vigilância sanitária. Cien Saude Colet 2010; 15(Supl. 3):3351-3360.

Artigo apresentado em 01/09/2014

Aprovado em 02/09/2014

Versão final apresentada em 08/09/2014 